\title{
Crédito e Exportações: uma Análise ao Nivel de Firma para os Países da América Latina*
}

\section{Credit and Exports: a Firm-level Analysis for the Countries of Latin America}

\author{
Marieli Vieira ${ }^{\mathrm{a}}$ \\ Gilberto Joaquim Fraga ${ }^{\mathrm{b}}$
}

\begin{abstract}
Resumo: O objetivo deste estudo é analisar como as restrições de crédito afetam a decisão de exportar de empresas em 18 países da América Latina. Realiza-se a investigação por meio da estimação de um modelo de probabilidade não linear (probit), utilizando-se dados de 7.764 firmas industriais. Os resultados indicam que o acesso ao crédito foi positivamente associado à decisão de participação das firmas no mercado internacional, o que indica a influência das restrições financeiras na probabilidade de exportação das empresas. Constata-se, também, que firmas maiores e com participação estrangeira na estrutura do capital têm mais chances de se tornarem exportadoras.
\end{abstract}

Palavras-chave: Restrições de crédito. Exportações. América Latina.

\begin{abstract}
This paper aims to analyze how credit constraints affect the chances to export from firms in eighteen countries in Latin America. The study used data from 7,764 industrial firms and a non-linear probability model (probit) was used the estimation. The results indicate that credit access is positively associated with the decision of the firms get into the international market, which confirm the influence of financial constraints on the probability of firms becoming exporter. It was also found that larger firms and with foreign share in the capital structure are more likely to export.
\end{abstract}

Keywords: Credit constraints. Export. Latin American.

JEL Classification: F12; F14.

\footnotetext{
* Os autores agradecem aos pareceristas pelos comentários e sugestões. Quaisquer erros remanescentes são de responsabilidade dos autores. $\mathrm{O}$ autor agradece o apoio financeiro do CNPq (APQ457620).

a Universidade Federal do Rio Grande do Sul (UFRGS), Programa de Pós-Graduação em Economia (PPGE). Porto Alegre, Rio Grande do Sul, Brasil.

b Universidade Estadual de Maringá (UEM), Departamento de Economia, Programa de Pós-graduação em Economia (PCE). Maringá, Paraná, Brasil.
} 


\section{1 lntrodução}

As exportações da América Latina cresceram significativamente entre 2000 e 2010. Registrou-se um crescimento de $22,4 \%$ ao ano, saindo de 384,17 bilhões de dólares, em 2000, para 946,69 bilhões de dólares, em 2010. No entanto, esse crescimento foi heterogêneo entre os países da região e, quando comparado com o crescimento mundial das exportações, as exportações da América Latina ocupavam 4,84\% das exportações globais em 2000 e, em 2010, aproximadamente 5\%, de acordo com os dados da Conferência das Nações Unidas no Comércio e Desenvolvimento (UNCTAD, 2016). Essa dinâmica das exportações dos países em desenvolvimento pode ser explicada, em parte, pela (in)existência de um bom mercado de crédito e acessível para as empresas.

O processo de produção para exportação é dependente do financiamento externo à empresa por três razões, de acordo com Manova, Wei e Zhang (2011). Em primeiro lugar, gera custos adicionais para as empresas, que incluem: a aprendizagem sobre os mercados para os quais exportarão; investimento em inovação e desenvolvimento; personalização do produto para atender às preferências dos consumidores estrangeiros; adaptações às regulamentações do país; pesquisa de marketing; criação e manutenção de redes de distribuição dos produtos no exterior; publicidade e compras de equipamentos de capital fixo; transportes; compra de insumos; e deveres e seguro de frete. Da mesma forma, as empresas que produzem para o mercado doméstico em relação às que produzem para exportação têm custos diferentes, pois estas têm de enfrentar gastos antes de qualquer receita da produção que entre em seus caixas e levam mais tempo para obter um retorno. A segunda razão é que o transporte de um país para outro e a entrega do produto levam mais tempo que as ordens domésticas, normalmente 60 dias a mais, o que agrava o capital de giro que os exportadores precisam. Terceiro, o risco maior que envolve o transporte faz com que os exportadores precisem obter seguro de comércio. Assim, produtores e exportadores nacionais rotineiramente dependem de capital proveniente de fontes externas às empresas porque eles incorrem em custos iniciais que não podem, por serem muito grandes, serem financiados pelos lucros acumulados ou pelo fluxo de caixa interno de operações.

Nesse cenário, emerge-se a seguinte questão: em que magnitude as restrições de crédito podem afetar as decisões de exportação das empresas industriais nos países da América Latina?

Baseadas nas teorias tradicionais de comércio, as pesquisas buscavam explicar o comportamento das exportações por análises de dados agregados por setores ou por países. A presente pesquisa tem como base o modelo de Roberts e Tybout (1997) - abordagem da nova teoria de comércio internacional - e buscará analisar como o potencial exportador é afetado pelas restrições de crédito em ní- 
vel microeconômico, utilizando-se de dados de firmas. Isso se torna relevante para a elaboração de políticas públicas de promoção da competitividade das empresas e de encorajamento para a expansão, como destacam Minetti e Zhu (2011), Alvarez e Lopez (2014) e Manole e Spatareanu (2015).

Considerando-se que a participação no comércio internacional é influenciada pelas imperfeições do mercado financeiro, pois as empresas necessitam de financiamentos para cobrir os custos e atender as exigências do mercado internacional, a hipótese a ser verificada é de que o acesso ao financiamento pode influenciar a participação nesse mercado. De acordo com Manova (2012), quando os mercados financeiros domésticos são bem desenvolvidos, as empresas têm melhor capacidade de financiar sua atividade de exportação, já que é mais fácil conseguir crédito no país do que no exterior. Para alcançar o objetivo proposto, utilizou-se um modelo probabilístico em que são estimados os parâmetros para variáveis que explicam a probabilidade de a empresa ser exportadora.

Como é bem documentado na literatura pertinente, a atividade de exportação é importante para o desenvolvimento econômico dos países, portanto esta pesquisa pode contribuir devido à importância de se entender a dinâmica das firmas exportadoras para a formulação de políticas de fomento.

A pesquisa está estruturada em mais cinco seções, além desta introdução: a segunda seção faz uma revisão dos estudos já realizados para diversos países que também buscaram identificar a influência do acesso ao crédito nas atividades exportadoras; a terceira seção aborda os impactos das restrições financeiras nas empresas, evidenciando a importância de um sistema financeiro bem desenvolvido disponível; a quarta seção apresenta as estatísticas descritivas e o modelo empírico empregado; a quinta seção expõe os resultados econométricos obtidos nas estimações; e, por fim, a sexta seção traça as considerações finais levando em conta as evidências encontradas.

\section{Literatura Empírica}

Essa seção busca apresentar uma revisão de literatura empírica relacionada. A literatura que relaciona as exportações ou decisões de exportar das firmas com o lado financeiro é recente e tem crescido nos últimos anos. Em parte, tal fato se deve às novas teorias de comércio internacional, como, por exemplo, as de Roberts e Tybout (1997), Melitz (2003) e Manova (2012), e, em parte, recente disponibilidade de dados em nível de firmas.

As "novas" teorias de comércio internacional atribuem papel relevante às características das firmas para entender o comportamento exportador. Valeri (2006) busca saber como as características das empresas de antes delas fazerem parte do mercado externo influenciaram a probabilidade de permanência destas na ativida- 
de exportadora, principalmente a questão da atividade inovadora. Os resultados encontrados por meio da estimação de modelos logit indicam que, se as empresas tiverem boa eficiência inicialmente, terão maior probabilidade de permanecer no mercado. Essa eficiência é determinada pela maior produtividade do trabalho, ganhos de escala e maior competitividade de custos. Esse resultado pode estar relacionado com a autosseleção, ou seja, a eficiência e a competitividade obtidas antes da entrada no mercado externo lhe proporcionaram melhores condições de sobreviver no mercado externo mais competitivo.

Greenaway, Guariglia e Kneller (2007), usando um painel com 9.292 firmas do setor de manufatura, estudaram as ligações entre as decisões financeiras das firmas do Reino Unido e sua participação no mercado de exportação para o período de 1993 a 2003. Os resultados indicam que os exportadores apresentam melhores condições financeiras que os não exportadores. Porém, quando as empresas exportadoras são diferenciadas entre exportadoras contínuas e entrantes, esse resultado é representado pelas primeiras, devido ao fato de que as empresas entrantes apresentam baixa liquidez e alta alavancagem, provavelmente devido aos custos irrecuperáveis para entrar no mercado de exportação.

Buscando verificar a existência de relação entre o acesso ao financiamento e as exportações, Du e Girma (2007) analisam como o investimento externo direto impacta o comportamento exportador das empresas manufatureiras chinesas no período de 1999 a 2002. Foram quatro os principais resultados: primeiro, quanto melhor o acesso ao crédito, maior a orientação para o mercado de exportação, principalmente em setores nos quais não sejam trabalho intensivo; segundo, quanto mais financiamento as empresas conseguem, mais o investimento externo direto causa aumento das exportações; terceiro, o mercado interno buscando investimento externo direto horizontal tem um efeito prejudicial sobre a orientação das empresas locais para o mercado de exportação; e último, são raros os efeitos positivos nas exportações que são causados pelas ligações verticais com as empresas multinacionais.

Bellone et al. (2008) analisam a relação entre as restrições financeiras e o comportamento para mais de 25.000 firmas industriais francesas no período de 1993 a 2005. De acordo com os autores, as firmas francesas que têm melhor saúde financeira (que é definida pelas variáveis tamanho, lucratividade, liquidez, capacidade de geração de fluxo de caixa, solvência, crédito comercial sobre os ativos totais e capacidade de pagamento) têm maiores chances de se tornarem exportadoras, pois as restrições financeiras são como uma barreira para a participação das exportações. Os autores sugerem que, quando há imperfeições financeiras, a intervenção pública pode ajudar as empresas a superarem os custos de entrada nos mercados de exportação. Stiebale (2011) também estuda empresas francesas no período entre 1998 e 2005 . Porém, segundo esse autor, não foram encontradas evidências de que as restrições financeiras importam para as decisões de 
exportação, indicando que talvez as empresas selecionadas não apresentem restrições financeiras ou que medidas públicas possam ter diminuído essas restrições financeiras.

Analisando as empresas da Bélgica, Muûls (2008) obtém resultados semelhantes para a interação entre as restrições de crédito e o comportamento das exportações de cerca de 9.000 empresas de manufatura entre 1999 e 2005. Consoante com o trabalho realizado por De Negri (2003) para o Brasil, os resultados da análise indicam que as empresas que possuem maior produtividade têm maior probabilidade de serem exportadoras, assim como aquelas que têm menos restrições de crédito. As restrições de crédito são importantes para determinar a margem extensiva (número de destinos ou de produtos exportados), mas não a intensiva (valor comercializado pelas firmas), em termos de destino. Já Li e Yu (2009) examinam como as empresas industriais chinesas e suas decisões de exportação são afetadas pelas restrições de crédito: os dados são de 160.000 empresas por ano no período de 2000 a 2007. Os autores observam que as empresas que são mais eficientes deverão ter maior probabilidade de sucesso em projetos de exportação, e isso facilita a obtenção de empréstimos.

Realizando uma análise das empresas paulistas nos anos de 1996 e 2001, Cava (2010) identifica quais os fatores que determinaram a atividade exportadora dessas empresas. Utilizando modelos probit e logit, o autor chegou a resultados que permitiram identificar determinantes da atividade exportadora das empresas como: o tamanho, a participação estrangeira no capital, a idade, importação e inovação tecnológica. Nessa mesma linha, Cole, Elliot e Virakul (2008) examinam a ligação entre as características das empresas e as suas decisões de participar dos mercados de exportação nas empresas tailandesas de 2001 a 2004. Os autores salientam que a liquidez determina significativamente a decisão de exportar, explicando, assim, a capacidade das empresas de investirem em custos de entrada no mercado de exportação. Outras características das empresas também podem ser consideradas importantes para a probabilidade de exportação.

Manova, Wei e Zhang (2011) estudam, ao nível da firma, como as restrições de crédito restringem o fluxo de comércio internacional e afetam o padrão setorial das atividades multinacionais na China no ano de 2005. Os autores constatam que as restrições de crédito afetam severamente as exportações totais das empresas, fazendo com que não possam entrar em outros mercados e diminuindo a sua diversidade de produtos de exportação. Já as filiais de multinacionais e joint ventures têm desempenho melhor que as empresas privadas nacionais nas exportações. Minetti e Zhu (2011) apresentam resultados semelhantes para as empresas italianas quando estimam o impacto das restrições de crédito às exportações em 4.680 empresas no ano de 2001. Os resultados indicam que a probabilidade de exportação é 39\% menor para as empresas que sofrem restrições de crédito. 
Analisando o setor de serviços, Lancheros e Demirel (2012) fizeram um estudo acerca da influência das finanças nas exportações para as empresas indianas no período de 1999 a 2007. O objetivo é avaliar se os empréstimos de curto e longo prazo influenciam na decisão de exportar e no volume exportado. Diante disso, não foram encontradas evidências de que as restrições de crédito influenciam na decisão de exportar e na quantidade exportada dessas empresas. Esse resultado sugere que a natureza dos custos das empresas que exportam serviços amortece o impacto das finanças sobre o comportamento de exportação.

A partir de uma base de dados para 38.207 firmas argentinas, Castagnino, D'amato e Sangiácomo (2013) investigam a importância do acesso ao financiamento para o desempenho de firmas em mercados exportadores no período de 2001 a 2006. Concluem que as firmas com mais acesso ao crédito têm maior probabilidade de exportar.

Alvarez (2013) busca saber sobre os determinantes do desempenho das firmas brasileiras estreantes no mercado internacional, como a probabilidade de sua sobrevivência e a evolução do valor exportado, especialmente sobre os impactos da utilização dos instrumentos de apoio drawback, ${ }^{1}$ BNDES Exim ${ }^{2}$ e Programa de Financiamento às Exportações (Proex). ${ }^{3}$ Os resultados indicam que as empresas beneficiadas por incentivos públicos têm maior probabilidade de sobrevivência e o valor médio exportado evolui de maneira mais rápida quando a empresa é beneficiada por um dos instrumentos. O autor explica que o resultado é esperado, pois os instrumentos auxiliam as empresas a superarem as restrições de crédito advindas dos custos associados à entrada no mercado internacional.

Entre os trabalhos realizados para grupos de países, Berman e Héricourt (2010) estudam como fatores financeiros afetam as decisões de exportação das empresas e o valor exportado pelas empresas a partir dos dados de 5.000 empresas de nove países em desenvolvimento e emergentes. No período entre 1998 a 2004 , os autores concluem que o acesso ao financiamento tem importância na decisão de entrada das empresas no mercado de exportação. As restrições financeiras criam uma desconexão entre a produtividade das empresas e seu estado de exportação, porém, quando o desenvolvimento financeiro melhora, essa desconexão diminui. Já o Wang (2010) apresenta um modelo com empresas heterogêneas na produtividade e descreve como elas crescem e relaxam suas restrições financeiras de forma que conseguem exportar ao longo do tempo. Por meio desse modelo, foi possível verificar o impacto das restrições de crédito no comportamento das

1 Instituído em 1966, consiste na suspensão ou eliminação de tributos incidentes sobre insumos importados para utilização em produto exportado.

2 Apoio do BNDES destinado à exportação de bens e serviços nacionais, podendo ser aplicado tanto na fase pré-embarque quanto na fase pós-embarque.

3 Programa do governo federal de financiamento às exportações brasileiras de bens e serviços voltado principalmente ao apoio das exportações de micro e pequenas empresas. 
empresas exportadoras. Nessa mesma linha, Hasan (2013) verifica se a disponibilidade de crédito é significativa para a decisão das empresas de realizar exportações e investimentos em máquinas e equipamentos. A pesquisa foi realizada nos anos de 2006 e 2010 para os seguintes países da América Latina: Argentina, Bolívia, Colômbia, Peru, México e Venezuela. Os resultados indicam que as empresas precisam de crédito, tanto para inovarem no seu processo de produção e inovarem e melhorarem os seus produtos, quanto para satisfazerem os custos de entrada no mercado de exportação.

Em um estudo realizado para 17 países em desenvolvimento, Fauceglia (2015) analisa se o desenvolvimento financeiro reduz o impacto das restrições de crédito sobre as decisões de exportação no período entre 2002 e 2005. O autor revela que o efeito positivo da liquidez de uma empresa sobre a probabilidade de exportação é maior para as empresas situadas em países menos desenvolvidos financeiramente. Esse fato destaca a importância do desenvolvimento do mercado financeiro reduzir as restrições de crédito. Os obstáculos de financiamento e os benefícios de um melhor acesso ao financiamento são elevados para empresas pertencentes a setores inovadores dependentes de financiamento externo.

Dessa forma, o objetivo desta seção foi fazer uma revisão de literatura de trabalhos que tratam da atividade exportadora ao nível da firma, buscando verificar padrões para as empresas exportadoras. A contribuição deste trabalho está na realização de uma pesquisa que envolve 18 países da América Latina, visto que há espaço na literatura já que os estudos que buscam verificar o impacto de características financeiras na probabilidade de exportação das empresas latino-americanas de forma desagregada são escassos.

\section{Modelo Teórico}

O impacto das restrições financeiras é diferenciado, sendo que alguns setores dependem mais do sistema financeiro do que outros. A literatura aponta que são dois os principais determinantes da vulnerabilidade financeira: em primeiro lugar, algumas empresas necessitam de mais capital financeiro devido aos custos iniciais elevados para realizarem investimentos em longo prazo, assim a duração dos ciclos de produção varia (RAJAN; ZINGALES, 1998); em segundo lugar, os setores variam sua dotação de ativos tangiveis que podem ser dados como garantia para obter financiamento externo (BRAUN, 2005; CLAESSENS; LAEVEN, 2003).

A presente pesquisa tem como base o modelo teórico de Roberts e Tybout (1997), que descreve a relação entre as características, restrições financeiras e a entrada no mercado de exportações. Nesse modelo, descreve-se a participação no mercado de exportações, considerando-se que as empresas buscam maximizar a sua receita de acordo com as informações que têm disponíveis sobre o mercado, 
como seus concorrentes e seus clientes. A função de lucro corrente 0 é uma combinação de receita corrente 0 e a diferença no valor esperado da receita maximizada se determinada empresa é exportadora ou não. A função de lucro corrente pode ser definida como apresentado na equação 1 :

$$
\hat{\pi}_{i t} \equiv R_{i t}+\delta\left[\left[E_{t}\left(V_{i(t+1)}\right)\left(\Omega_{i(t+1)}\right) \mid Y_{i t}=1\right]-\delta\left[E_{t}\left(V_{i(t+1)}\right)\left(\Omega_{i(t+1)}\right) \mid Y_{i t}=0\right]\right]
$$

em que $\mathrm{Y}_{\mathrm{it}}$ é o status de exportação; $\delta$ é a taxa de desconto; $\mathrm{V}_{\mathrm{i}(t+1)}$ é o valor de retorno maximizado esperado; $\Omega_{i(t+1)}$ é o conjunto de informações futuras da empresa $i$; e $E_{t}$ é o valor esperado em um determinado conjunto de informações.

Quando a empresa é capaz de identificar qual o seu lucro esperado, ela pode decidir se quer ou não entrar no mercado de exportações ou, até mesmo, decidir sair, de acordo com a equação 2:

$$
Y_{i t}=\left\{\begin{array}{c}
1 \text { se } \hat{\pi}_{\text {it }}-c_{i t}+S_{i}\left(1-Y_{i(t-1)}\right) \\
0 \text { caso contrário }
\end{array}\right.
$$

Na equação 2, a empresa i no tempo $t$ escolhe exportar se a receita e o lucro bruto previstos $\left(\hat{\pi}_{i t}\right)$ menos o custo corrente do período $\left(C_{t i}\right)$, junto com os custos de entrada $\left(S_{\mathrm{i}}\right)$, forem positivos. Esse custo de entrada está associado à aprendizagem sobre cada mercado consumidor, pesquisa de marketing, publicidade, criação de redes de distribuição e adaptação às regulamentações do país.

Roberts e Tybout (1997) explicam também que a decisão de exportação de uma empresa não só depende de seu lucro e receita, mas também de diferentes características das empresas $\left(Z_{i t}\right)$, como o tamanho, a idade, a utilização de mão de obra qualificada, a presença de capital estrangeiro, a utilização de insumos importados, a utilização de meios de comunicação para contato com os fornecedores e clientes e a proximidade de outras empresas do setor. Portanto, o modelo pode ser representado assim:

$$
Y_{i t}=\left\{\begin{array}{c}
1 \text { se } \beta Z_{i t}-S_{i}\left(1-Y_{i(t-1)}\right)+\varepsilon_{i t} \geq 0 \\
0 \text { caso contrário }
\end{array}\right.
$$

Muitos estudos, como os de Melitz (2003), Bernard e Jensen (2004), Greenaway, Guariglia e Kneller (2007), Wagner (2007), Kannebley Júnior et al. (2009), Cole, Elliot e Virakul, (2008), Stiebale (2011), Lancheros e Demirel (2012) e Fauceglia (2015), se baseiam e/ou avançam em relação a esse modelo de Roberts e Tybout (1997), assim como este trabalho, e o estendem para verificar o impacto de características e fatores que influenciam a decisão de exportação. O avanço deste trabalho em relação aos demais é em relação à análise desagregada das firmas para um conjunto de países. 


\section{Estratégia Empírica}

Na primeira subseção busca-se apresentar tanto a distribuição das empresas (\%) exportadoras e não exportadoras nos países da amostra quanto o porte (tamanho) das firmas analisadas de acordo com o status exportador. Também, destacam-se os principais tipos de obstáculos para as atividades (Gráfico 1) das firmas. A especificação empírica para estimativas e testes consta na subseção 4.2.

\subsection{Dados e Estatística Descritiva}

A análise empírica se baseia nos dados de mais de 7.764 firmas distribuídas em 18 países da América Latina, obtidos do Banco Mundial. De acordo com o Banco Mundial (THE WORD BANK, 2016), essa coleta de dados dos setores-chave industriais e de serviços ocorre em todas as regiões do mundo. Os questionários aplicados nos países são padronizados, por isso há uma metodologia uniforme que permite que os erros de medição sejam minimizados e seja possível a comparação de todos os países.

Os questionários são divididos por setor de atividade, tamanho da empresa e sua localização geográfica. A estratificação pelo tamanho da empresa segue três divisões: as pequenas empresas, que possuem de 5 a 19 funcionários; as médias empresas, de 20 a 99 funcionários; e as grandes empresas, com 100 ou mais funcionários.

A divisão pela distribuição geográfica reflete a distribuição da atividade não econômica do país. Na maioria dos países, isso significa incluir os principais centros urbanos ou regiões do país, já que a maioria da atividade não agrícola está agrupada nos grandes centros populacionais.

A divisão por setor de atividade depende do tamanho da economia, medido pelo rendimento nacional bruto (RNB). Conforme explica o Banco Mundial (THE WORD BANK, 2016), as economias classificadas como muito pequenas, com RNB de até U\$15 bilhões, são divididas em dois grupos: fabricação e resto da economia não agrícola. As classificadas como pequenas economias, com RNB entre U\$15 e U\$100 bilhões, são divididas em manufatura, varejo e resto da economia não agrícola. Nas economias de tamanho médio, que possuem RNB entre U\$100 e U\$500 bilhões, destacam-se as quatro indústrias mais importantes do país, um estrato adicional é composto pelo resto das indústrias transformadoras e os dois estratos finais são compostos por varejo e resto da economia não agrícola. Nas grandes economias, com RNB maior que $\mathrm{U} \$ 500$ bilhões, a divisão é feita em seis setores da indústria transformadora, mais um estrato com o restante das indústrias transformadoras, e o varejo e a economia não agrícola completam a amostra. 
Os questionários às empresas focam em fatores que influenciam o ambiente de negócios nos locais onde atuam as firmas. Esses fatores podem fazer com que as empresas fiquem acomodadas, com que sejam limitadas e são importantes para saber se o país irá prosperar ou não. O Banco Mundial (THE WORD BANK, 2016) explica que um bom ambiente de negócios, caracterizado pelo acesso ao crédito por parte das empresas, contribui para que estas operem de maneira eficiente e reforça os incentivos para que inovem, melhorem fatores chave para aumentar a sua produtividade e busquem o desenvolvimento sustentável. Em contrapartida, um ambiente de negócios ruim caracteriza-se pelas dificuldades na obtenção de crédito e, assim, de investimentos e faz com que existam obstáculos à realização de atividades e diminuem as perspectivas do país em alcançar um bom desenvolvimento. De acordo com Manole e Spatareanu (2015), o ambiente de negócios ou clima de investimentos impacta diretamente a capacidade de exportar, sendo que, para as empresas africanas, por exemplo, ele age como uma barreira comercial e afeta a propensão das empresas de venderem em mercados externos.

Os questionários conduzidos pelo Banco Mundial e seus parceiros nos países são administrados a uma amostra representativa de empresas na economia formal privada não agrícola. Fazem parte da pesquisa os setores de fabricação, serviços e os setores de transporte e construção, enquanto são excluídos os setores que prestam serviços de utilidade pública, serviços públicos, saúde, setores não financeiros e o setor agrícola (THE WORD BANK, 2016).

Para a realização desta pesquisa, foi selecionada uma amostra aleatória de 7.764 empresas industriais que atuam nestes setores: alimentos, tabaco, têxtil, vestuário, couro, madeira, papel, suportes para gravação, produtos petrolíferos refinados, químicos, plásticos e borracha, produtos minerais não metálicos, metais básicos, máquinas e equipamentos, eletrônicos, instrumentos de precisão, máquinas de transporte, móveis e reciclagem.

As empresas que se classificam no setor de serviços não são consideradas nessa amostra, uma vez que os países da América Latina não são grandes exportadores nesse setor. Como apresentado por Lima, Herreros e Mulder. (2011), dos 18 países da América Latina analisados, apenas cinco apresentaram saldos positivos na década de 2000, o que não compensa os déficits apresentados dos demais nos setores de serviços.

Na Tabela 1 são mostrados os 18 países da América Latina estudados, o ano da pesquisa para cada país e o número total de empresas exportadoras e não exportadoras. 
Tabela 1 - Empresas exportadoras e não exportadoras por país (2009-2010)

\begin{tabular}{lcccc}
\hline País & $\begin{array}{c}\text { Ano da } \\
\text { pesquisa }\end{array}$ & $\begin{array}{c}\text { Número de } \\
\text { empresas } \\
\text { exportadoras }\end{array}$ & $\begin{array}{c}\text { Número de empresas } \\
\text { não exportadoras }\end{array}$ & $\begin{array}{c}\text { Número total de } \\
\text { empresas }\end{array}$ \\
\hline Argentina & 2010 & 375 & 418 & 793 \\
Bolívia & 2010 & 30 & 112 & 142 \\
Brasil & 2009 & 228 & 1114 & 1342 \\
Chile & 2010 & 243 & 534 & 777 \\
Colômbia & 2010 & 243 & 463 & 706 \\
Costa Rica & 2010 & 113 & 213 & 326 \\
Equador & 2010 & 29 & 90 & 119 \\
El Salvador & 2010 & 68 & 57 & 125 \\
Guatemala & 2010 & 122 & 233 & 355 \\
Guiana & 2010 & 50 & 115 & 165 \\
Honduras & 2010 & 24 & 126 & 150 \\
Jamaica & 2010 & 33 & 88 & 121 \\
México & 2010 & 298 & 859 & 1157 \\
Nicarágua & 2010 & 21 & 105 & 126 \\
Panamá & 2010 & 5 & 110 & 115 \\
Paraguai & 2010 & 34 & 91 & 125 \\
Peru & 2010 & 289 & 471 & 760 \\
Uruguai & 2010 & 127 & 233 & 360 \\
\hline Total & & 2.332 & 5.432 & 7.764 \\
\hline
\end{tabular}

Fonte: Elaboração própria a partir de The World Bank (2016).

Para o Brasil, usa-se o ano de pesquisa 2009, pois é a última pesquisa disponível. É possível perceber que todos os países possuem número maior de empresas não exportadoras, exceto El Salvador, o único em que o número de exportadoras, $54,40 \%$, supera o número de não exportadoras. Brasil e México são os países com o maior número de empresas na amostra, 1.342 e 1.157, respectivamente, sendo o percentual de exportadoras nesses dois países de $17 \%$ e 25,8\%, respectivamente. Ao todo, fazem parte da amostra, 2.332 empresas exportadoras e 5.432 empresas não exportadoras.

A Tabela 2 apresenta a divisão das empresas entre exportadoras e não-exportadoras, para cada faixa de tamanho, em cada país incluído na pesquisa. 
Tabela 2 - Distribuição das empresas (\%) exportadoras e não exportadoras: países selecionados da América Latina

\begin{tabular}{lllllll}
\hline \multicolumn{4}{l}{ Exportadoras } & \multicolumn{4}{l}{ Não exportadoras } \\
\hline País & Pequena & Média & Grande & Pequena & Média & Grande \\
\hline Argentina & 6,68 & 17,65 & 22,95 & 23,20 & 20,18 & 9,33 \\
Bolívia & 1,41 & 4,93 & 14,79 & 26,06 & 30,28 & 22,54 \\
Brasil & 1,19 & 5,81 & 9,99 & 33,76 & 37,85 & 11,40 \\
Chile & 1,93 & 9,40 & 19,95 & 28,70 & 29,86 & 10,17 \\
Colômbia & 2,83 & 11,76 & 19,83 & 30,88 & 25,35 & 9,35 \\
Costa Rica & 3,99 & 12,88 & 17,79 & 34,66 & 26,38 & 4,29 \\
Equador & 1,68 & 8,40 & 14,29 & 30,25 & 27,73 & 17,65 \\
El Salvador & 4,80 & 21,60 & 28,00 & 24,80 & 12,00 & 8,80 \\
Guatemala & 2,82 & 12,11 & 19,44 & 34,08 & 19,44 & 12,11 \\
Guiana & 6,06 & 11,52 & 12,73 & 24,85 & 32,12 & 12,73 \\
Honduras & 2,00 & 4,67 & 9,33 & 41,33 & 30,00 & 12,67 \\
Jamaica & 4,96 & 7,44 & 14,88 & 31,40 & 30,58 & 10,74 \\
México & 1,73 & 7,43 & 16,59 & 32,50 & 25,67 & 16,08 \\
Nicarágua & 2,38 & 3,97 & 10,32 & 42,06 & 32,54 & 8,73 \\
Panamá & 0,00 & 0,87 & 3,48 & 33,04 & 47,83 & 14,78 \\
Paraguai & 1,60 & 12,80 & 12,80 & 23,20 & 33,60 & 16,00 \\
Peru & 2,76 & 12,50 & 22,76 & 27,50 & 24,47 & 10,00 \\
Uruguai & 6,11 & 10,83 & 18,33 & 34,72 & 22,78 & 7,22 \\
\hline
\end{tabular}

Fonte: Elaboração própria a partir de The World Bank (2016).

A partir das informações da Tabela 2, percebe-se um padrão para todos os países quando se trata das empresas exportadoras: o percentual de distribuição é crescente de acordo com o tamanho, o que significa que, quanto maior a empresa, maior a concentração de empresas exportadoras. Esse fato corrobora o estudo de Pinheiro e Moreira (2000), que diz que o tamanho da empresa é uma influência importante na probabilidade de uma empresa ser exportadora.

O Panamá é o país que possui o menor percentual de empresas exportadoras em todos os tamanhos, sendo que não há pequenas empresas que exportam e o percentual de exportadoras médias e grandes é de $0,87 \%$ e 3,48\%, respectivamente. El Salvador (28\%), Argentina (22,95\%) e Peru (22,76\%) são os países que apresentam o maior percentual de grandes empresas exportadoras.

Com relação às empresas não exportadoras, é possível observar diferenças. Quanto menor o tamanho da empresa, maior o percentual de empresas não exportadoras - com exceção de Bolívia, Brasil, Chile, Guiana, Panamá e Paraguai, 
em que a maior concentração de empresas não exportadoras são as de tamanho médio. Essas observações podem significar que as pequenas e médias empresas têm dificuldades em participar do mercado internacional, conforme Ciani e Bartoli (2013), que, estudando as pequenas e médias empresas industriais italianas, concluíram que as restrições de crédito tornam a empresa menos propensa a aumentar a sua qualidade para exportação.

A Tabela 3 expressa a distribuição do percentual de empresas exportadoras e não exportadoras da amostra em cada faixa de tamanho - medida em número de pessoas ocupadas.

Tabela 3 - Distribuição das empresas exportadoras e não exportadoras: tamanho (percentual do total), de 2009 a 2010

\begin{tabular}{llll}
\hline Tamanho & Exportadoras (\%) & $\begin{array}{l}\text { Não exportadoras } \\
(\%)\end{array}$ & Total \\
\hline Pequena $(<20)$ & 2,89 & 30,74 & 33,63 \\
Média (de 20 a 99) & 10,05 & 27,86 & 37,91 \\
Grande (100 ou mais) & 17,10 & 11,36 & 28,46 \\
\hline Total & 30,04 & 69,96 & 100,00 \\
\hline
\end{tabular}

Fonte: Elaboração própria a partir de The World Bank (2016).

A concentração de empresas não exportadoras é maior quando se trata das empresas pequenas e médias, apesar da diferença diminuir bastante entre as exportadoras e não exportadoras de porte médio. Essas duas primeiras faixas de tamanho (menor que 20 e de 20 a 99 pessoas ocupadas) concentram cerca de $71 \%$ do total das empresas. A maior concentração está na faixa de 20 a 99 pessoas ocupadas, são 2.943 empresas, representando 37,91\% do total de empresas. Porém, quando se fala das empresas de grande porte, aquelas que possuem 100 ou mais trabalhadores, $17,10 \%$ são exportadoras, enquanto $11,36 \%$ não são exportadoras.

Os elementos do ambiente de negócios listados como maiores obstáculos para as atividades atuais das empresas em cada país estão no Quadro 1. Pode-se perceber a importância de cada elemento, pois esse indicador resume o percentual de empresas de cada país que indicaram cada um dos vários obstáculos listados como o de maior importância para seu estabelecimento. Esse indicador pode auxiliar os formuladores de políticas públicas a definirem prioridades ao criarem programas e políticas voltadas para a melhoria do ambiente propício às empresas. 
Quadro 1 - Cinco principais obstáculos às atividades das empresas em cada país (\%)

\begin{tabular}{|c|c|c|c|c|c|}
\hline País & $1^{\circ}$ & $2^{\circ}$ & $3^{\circ}$ & $4^{\circ}$ & $5^{\circ}$ \\
\hline Argentina & $\begin{array}{l}\text { Regulações de } \\
\text { trabalho }(17,56 \%)\end{array}$ & $\begin{array}{l}\text { Instabilidade } \\
\text { política }(15,36 \%)\end{array}$ & $\begin{array}{l}\text { Acesso ao } \\
\text { financiamento } \\
(13,92 \%)\end{array}$ & \begin{tabular}{|l|} 
Práticas de \\
competidores \\
informais \\
$(12,76 \%)$ \\
\end{tabular} & Impostos $(10,94)$ \\
\hline Bolívia & \begin{tabular}{|l|} 
Práticas de \\
competidores \\
informais \\
$(32,75 \%)$ \\
\end{tabular} & $\begin{array}{l}\text { Instabilidade } \\
\text { política }(20,87 \%)\end{array}$ & $\begin{array}{l}\text { Força de trabalho } \\
\text { desqualificada } \\
(9,86 \%)\end{array}$ & $\begin{array}{l}\text { Acesso ao } \\
\text { financiamento } \\
(7,83 \%)\end{array}$ & $\begin{array}{l}\text { Regulações do } \\
\text { trabalho }(7,83 \%)\end{array}$ \\
\hline Brasil & $\begin{array}{l}\text { Impostos } \\
(31,33 \%)\end{array}$ & $\begin{array}{l}\text { Práticas de } \\
\text { competidores } \\
\text { informais } \\
(12,26 \%)\end{array}$ & $\begin{array}{l}\text { Força de trabalho } \\
\text { desqualificada } \\
(12,15 \%)\end{array}$ & $\begin{array}{l}\text { Administração } \\
\text { fiscal }(9,84 \%)\end{array}$ & $\begin{array}{l}\text { Acesso ao } \\
\text { financiamento } \\
(9,79 \%)\end{array}$ \\
\hline Chile & \begin{tabular}{|l|} 
Regulações do \\
trabalho $(18,98 \%)$
\end{tabular} & $\begin{array}{l}\text { Força de trabalho } \\
\text { desqualificada } \\
(18 \%)\end{array}$ & $\begin{array}{l}\text { Práticas de } \\
\text { competidores } \\
\text { informais }(13,80 \%)\end{array}$ & $\begin{array}{l}\text { Acesso ao } \\
\text { financiamento } \\
(13,01 \%)\end{array}$ & $\begin{array}{l}\text { Eletricidade } \\
(12,82 \%)\end{array}$ \\
\hline Colômbia & $\begin{array}{l}\text { Práticas de } \\
\text { competidores } \\
\text { informais } \\
(33,09 \%) \\
\end{array}$ & $\begin{array}{l}\text { Acesso ao } \\
\text { financiamento } \\
(16,06 \%)\end{array}$ & Impostos (10\%) & $\begin{array}{l}\text { Força de trabalho } \\
\text { desqualificada } \\
(9,26 \%)\end{array}$ & $\begin{array}{l}\text { Regulações do } \\
\text { trabalho }(5,96 \%)\end{array}$ \\
\hline Costa Rica & \begin{tabular}{|l} 
Práticas de \\
competidores \\
informais \\
$(23,33 \%)$ \\
\end{tabular} & $\begin{array}{l}\text { Acesso ao } \\
\text { financiamento } \\
(20,84 \%)\end{array}$ & $\begin{array}{l}\text { Licenciamento } \\
\text { e autorizações } \\
(10,52 \%)\end{array}$ & $\begin{array}{l}\text { Força de trabalho } \\
\text { desqualificada } \\
(9,94 \%)\end{array}$ & $\begin{array}{l}\text { Eletricidade } \\
(6,12 \%)\end{array}$ \\
\hline Equador & $\begin{array}{l}\text { Instabilidade } \\
\text { política }(19,23 \%)\end{array}$ & $\begin{array}{l}\text { Práticas de } \\
\text { competidores } \\
\text { informais } \\
(16,48 \%)\end{array}$ & $\begin{array}{l}\text { Acesso ao } \\
\text { financiamento } \\
(13,19 \%)\end{array}$ & $\begin{array}{l}\text { Força de trabalho } \\
\text { desqualificada } \\
(8,79 \%)\end{array}$ & $\begin{array}{l}\text { Regulações do } \\
\text { trabalho }(8,52 \%)\end{array}$ \\
\hline El Salvador & \begin{tabular}{|l} 
Práticas de \\
competidores \\
informais $(32,26)$ \\
\end{tabular} & $\begin{array}{l}\text { Acesso ao } \\
\text { financiamento } \\
(16,94) \\
\end{array}$ & $\begin{array}{l}\text { Crime, roubo e } \\
\text { desordem }(15,32)\end{array}$ & $\begin{array}{l}\text { Instabilidade } \\
\text { política }(13,71)\end{array}$ & $\begin{array}{l}\text { Força de trabalho } \\
\text { desqualificada } \\
(5,65)\end{array}$ \\
\hline Guatemala & $\begin{array}{l}\text { Práticas de } \\
\text { competidores } \\
\text { informais }(22,82)\end{array}$ & $\begin{array}{l}\text { Instabilidade } \\
\text { política }(16,90)\end{array}$ & $\begin{array}{l}\text { Crime, roubo e } \\
\text { desordem }(13,80)\end{array}$ & $\begin{array}{l}\text { Corrupção } \\
(10,70)\end{array}$ & $\begin{array}{l}\text { Força de trabalho } \\
\text { desqualificada } \\
(10,42)\end{array}$ \\
\hline Guiana & $\begin{array}{l}\text { Força de trabalho } \\
\text { desqualificada } \\
(17,28)\end{array}$ & $\begin{array}{l}\text { Práticas de } \\
\text { competidores } \\
\text { informais }(13,58)\end{array}$ & Impostos $(11,11)$ & $\begin{array}{l}\text { Eletricidade } \\
(9,88)\end{array}$ & $\begin{array}{l}\text { Regulação } \\
\text { alfandegária e } \\
\text { comercial }(9,26)\end{array}$ \\
\hline Honduras & $\begin{array}{l}\text { Corrupção } \\
(19,33)\end{array}$ & $\begin{array}{l}\text { Acesso ao } \\
\text { financiamento } \\
(18,67)\end{array}$ & $\begin{array}{l}\text { Instabilidade política } \\
(12,67)\end{array}$ & $\begin{array}{l}\text { Crime, roubo e } \\
\text { desordem }(9,33)\end{array}$ & $\begin{array}{l}\text { Práticas de } \\
\text { competidores } \\
\text { informais }(8,67)\end{array}$ \\
\hline Jamaica & Impostos $(29,17)$ & $\begin{array}{l}\text { Eletricidade } \\
(24,17)\end{array}$ & $\begin{array}{l}\text { Acesso ao } \\
\text { financiamento } \\
(10,00)\end{array}$ & $\begin{array}{l}\text { Força de trabalho } \\
\text { desqualificada } \\
(9,17)\end{array}$ & $\begin{array}{l}\text { Práticas de } \\
\text { competidores } \\
\text { informais }(8,33)\end{array}$ \\
\hline México & \begin{tabular}{|l} 
Práticas de \\
competidores \\
informais $(16,51)$ \\
\end{tabular} & Impostos $(13,54)$ & $\begin{array}{l}\text { Acesso ao } \\
\text { financiamento } \\
(10,39)\end{array}$ & $\begin{array}{l}\text { Corrupção } \\
(10,22)\end{array}$ & $\begin{array}{l}\text { Força de trabalho } \\
\text { desqualificada } \\
(9,87)\end{array}$ \\
\hline Nicarágua & $\begin{array}{l}\text { Eletricidade } \\
(33,33)\end{array}$ & $\begin{array}{l}\text { Práticas de } \\
\text { competidores } \\
\text { informais }(18,25)\end{array}$ & $\begin{array}{l}\text { Instabilidade política } \\
(14,29)\end{array}$ & $\begin{array}{l}\text { Acesso ao } \\
\text { financiamento } \\
(11,11)\end{array}$ & Impostos $(7,14)$ \\
\hline
\end{tabular}

Continua... 
Conclusão.

\begin{tabular}{|c|c|c|c|c|c|}
\hline País & $1^{\circ}$ & $2^{\circ}$ & $3^{\circ}$ & $4^{\circ}$ & $5^{\circ}$ \\
\hline Panamá & $\begin{array}{l}\text { Práticas de } \\
\text { competidores } \\
\text { informais }(22,92)\end{array}$ & $\begin{array}{l}\text { Crime, roubo e } \\
\text { desordem }(16,67)\end{array}$ & Corrupção $(11,46)$ & $\begin{array}{l}\text { Força de trabalho } \\
\text { desqualificada } \\
(10,42)\end{array}$ & $\begin{array}{l}\text { Licenciamento } \\
\text { e autorizações } \\
(7,29)\end{array}$ \\
\hline Paraguai & $\begin{array}{l}\text { Práticas de } \\
\text { competidores } \\
\text { informais }(30,65)\end{array}$ & $\begin{array}{l}\text { Força de trabalho } \\
\text { desqualificada } \\
(14,52)\end{array}$ & Corrupção $(9,68)$ & $\begin{array}{l}\text { Acesso ao } \\
\text { financiamento } \\
(12,10)\end{array}$ & $\begin{array}{l}\text { Regulações do } \\
\text { trabalho }(5,65)\end{array}$ \\
\hline Peru & $\begin{array}{l}\text { Práticas de } \\
\text { competidores } \\
\text { informais }(30,17)\end{array}$ & $\begin{array}{l}\text { Força de trabalho } \\
\text { desqualificada } \\
(13,04)\end{array}$ & $\begin{array}{l}\text { Acesso ao } \\
\text { financiamento }(9,49)\end{array}$ & Impostos $(7,11)$ & Corrupção $(7,11)$ \\
\hline Uruguai & $\begin{array}{l}\text { Práticas de } \\
\text { competidores } \\
\text { informais }(32,38)\end{array}$ & $\begin{array}{l}\text { Regulações do } \\
\text { trabalho }(16,33)\end{array}$ & Impostos $(14,90)$ & $\begin{array}{l}\text { Força de trabalho } \\
\text { desqualificada } \\
(12,61)\end{array}$ & $\begin{array}{l}\text { Acesso ao } \\
\text { financiamento } \\
(8,60)\end{array}$ \\
\hline
\end{tabular}

Fonte: Elaboração própria a partir de dados de The World Bank (2016).

É possível verificar, de acordo com o Quadro 1, que, em 15 dos 18 países da América Latina incluídos na pesquisa, o acesso ao financiamento está classificado entre os cinco principais obstáculos às atividades das empresas, o que indica que realmente as restrições financeiras afetam as atividades das empresas, podendo, inclusive, afetar a sua decisão e restringir a sua capacidade de exportar, conforme apontaram Manova, Wei e Zhang (2011).

O Quadro 1 indica que, na Costa Rica, o acesso ao financiamento foi escolhido pela maior proporção de empresas como o principal obstáculo que afeta as atividades das empresas, 23,03\%, enquanto Argentina, Colômbia, El Salvador e Honduras têm o acesso ao financiamento classificado como segundo obstáculo mais severo contra as atividades empresariais, com as proporções de $14,85 \%$, $17,02 \%, 16,94 \%$ e 18,67\% respectivamente. No Brasil, o acesso ao financiamento está em quinto lugar, indicado por 10,26\% das empresas.

No Gráfico 1, pode-se ver a proporção de empresas que indicaram cada um dos obstáculos listados na pesquisa como obstáculo mais severo contra as atividades das empresas. 
Gráfico 1 - Percentual de empresas por principal tipo de obstáculo às atividades: países da América Latina, de 2009 a 2010 (\%)

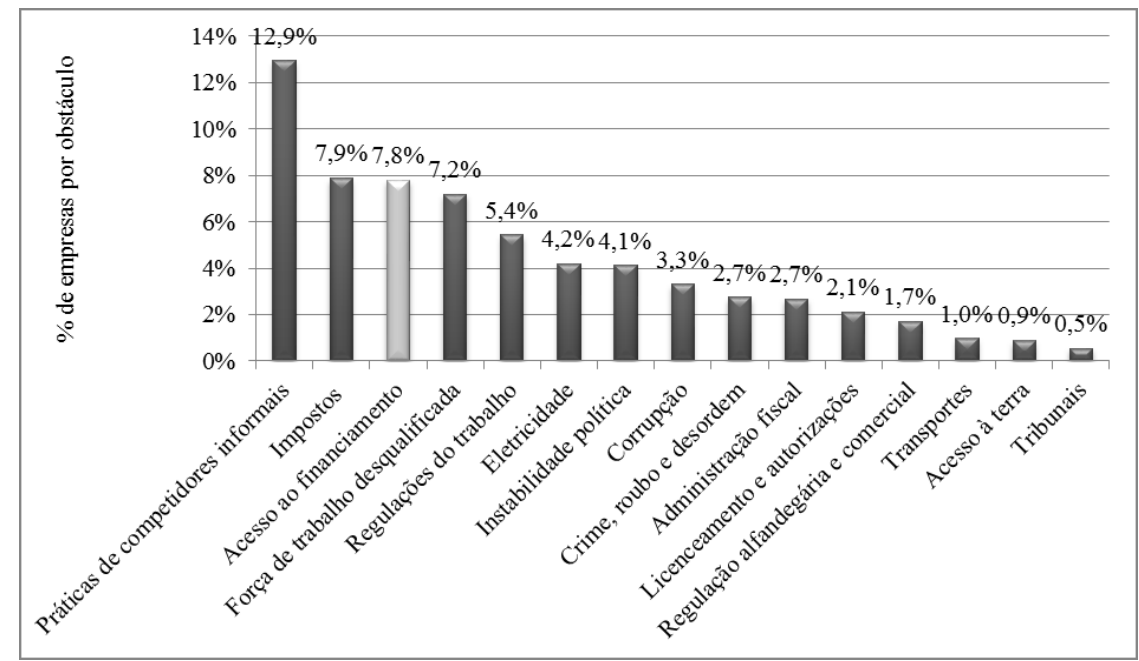

Fonte: Elaboração própria a partir de The World Bank (2016).

Em primeiro lugar, estão as práticas dos competidores informais, que atuam na economia informal, eleitas por 12,9\% das empresas como o obstáculo mais severo, seguidos dos impostos, escolhido por 7,9\% das empresas. Em terceiro lugar, está o foco do presente estudo, o acesso ao financiamento, considerado como principal obstáculo às atividades de 7,8\% das empresas. Portanto, uma melhora no mercado de crédito, que diminuirá a restrição de crédito para as firmas, poderá contribuir para aumentar as chances de as empresas participarem do comércio mundial.

O Gráfico 2 apresenta a dificuldade do acesso ao financiamento e a distribuição das empresas. 
Gráfico 2 - Empresas por grau de dificuldade imposto para o acesso ao financiamento: percentual do total geral (\%)

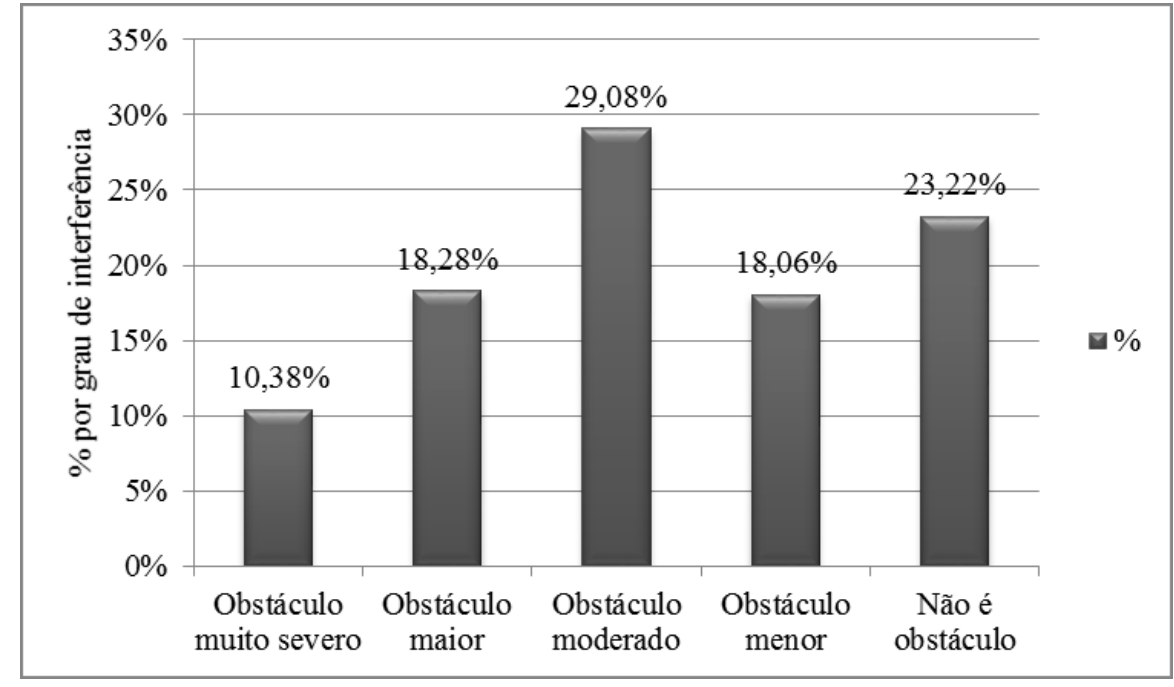

Fonte: Elaboração própria a partir de The World Bank (2016).

O acesso ao financiamento é considerado um obstáculo muito severo por $10,38 \%$ das empresas, o maior obstáculo por $18,28 \%$, um obstáculo moderado por $29,08 \%$, o menor obstáculo por $18,06 \%$, enquanto $23,22 \%$ não consideram que seja um obstáculo às suas atividades. No total, 75,8\% das empresas consideram que o acesso ao financiamento impõe alguma forma de obstáculo às atividades das empresas, de forma que, apesar de as empresas procurarem se estabelecer onde esse obstáculo não é um problema, ele continua a ser um empecilho.

$\mathrm{Na}$ Tabela 4, é possível observar o percentual de empresas por faixa de tamanho e proporção do capital de giro financiado por fundos internos ou por bancos privados ou estatais, assim como dos ativos fixos.

Tabela 4 - Distribuição das empresas por faixa de tamanho e origem do capital de giro e dos ativos fixos (\%)

\begin{tabular}{lcccc}
\hline & & $0 \%$ & $1 \%$ a $50 \%$ & $51 \%$ a $100 \%$ \\
\hline Capital de giro & & $(1)$ & $(2)$ & $(3)$ \\
\hline \multirow{3}{*}{ Fundos internos } & Pequena & 6,07 & 8,86 & 18,78 \\
& Média & 7,17 & 12,83 & 17,91 \\
& Grande & 5,28 & 9,71 & 13,39 \\
\hline
\end{tabular}

Continua... 
Conclusão...

\begin{tabular}{lcccc}
\hline & & $0 \%$ & $1 \%$ a $50 \%$ & $51 \%$ a $100 \%$ \\
\hline Capital de giro & & $(1)$ & $(2)$ & $(3)$ \\
\hline \multirow{2}{*}{ Emprestado de } & Pequena & 23,09 & 8,32 & 2,29 \\
bancos & Média & 19,44 & 14,32 & 4,15 \\
& Grande & 11,91 & 12,11 & 4,37 \\
\hline Ativos fixos & & & & \\
\hline \multirow{4}{*}{ Fundos internos } & Pequena & 6,50 & 4,57 & 12,34 \\
& Média & 11,45 & 9,63 & 17,99 \\
& Grande & 10,94 & 8,91 & 17,67 \\
Emprestado de & Pequena & 16,40 & 3,05 & 3,96 \\
bancos & Média & 23,28 & 6,39 & 9,40 \\
& Grande & 20,51 & 6,73 & 10,29 \\
\hline
\end{tabular}

Fonte: Elaboração própria a partir de The World Bank (2016).

A entrevista do Banco Mundial (2010) fornece indicadores de como as empresas financiam suas operações, que comparam o uso relativo de várias fontes de financiamento do investimento: fundos internos ou lucros acumulados, contribuição dos proprietários ou emissão de novas ações, empréstimos de bancos privados ou estatais, empréstimos de instituições financeiras não bancárias, compras a crédito de fornecedores e adiantamentos de clientes e outros (como agiotas, amigos, parentes, obrigações, etc.).

As faixas percentuais de financiamento do capital de giro e dos ativos fixos são três: quando $0 \%$ é financiado; quando $1 \%$ a $50 \%$ é financiado; e quando $51 \%$ a $100 \%$ é financiado. Porém, cabe ressaltar que as empresas destacadas nessas faixas se classificam apenas no financiamento por bancos privados ou estatais e financiamento por fundos próprios, sendo que aquelas que não são financiadas por uma dessas duas fontes podem, ainda, ser financiadas por qualquer uma das outras fontes incluídas na pesquisa, porém não se encaixam no objeto de estudo desta pesquisa.

Para as empresas que possuem o capital de giro ${ }^{4}$ financiado pelos fundos internos, independente da faixa de tamanho, maior é o percentual de empresas em cada nível quanto maior o percentual do capital de giro financiado. Quando o capital de giro é financiado por bancos privados ou estatais, menor é o percentual de empresas em cada nível quanto maior o percentual de capital de giro financiado.

A mesma lógica não pode ser seguida quando os ativos fixos ${ }^{5}$ são financiados pelos fundos internos, como verificado na Tabela 4: a proporção de empresas pequenas, médias e grandes é maior quando os ativos fixos não são financiados ou

$4 \quad$ Capital necessário para continuar as atividades da empresa.

5 Tais como máquinas, equipamentos, terrenos ou edifícios. 
quando o percentual financiado é de $51 \%$ a $100 \%$. A proporção de empresas que possuem de $1 \%$ a $50 \%$ dos ativos fixos financiados pelos fundos internos é menor. Porém, quando os ativos fixos são financiados pelos bancos privados ou estatais, a maior proporção das empresas não tem seus ativos fixos financiados.

Falando-se das empresas que não possuem capital de giro financiado por fundos internos, observando-se a Tabela 4, ainda pode-se ver que a diferença entre as faixas de tamanho não é grande. Contudo, quando se observa as empresas que não têm capital de giro financiado pelos bancos privados ou estatais, percebe-se que o número de pequenas empresas aumenta significativamente se comparado às não financiadas pelos fundos internos. Para as empresas que possuem de $51 \%$ a $100 \%$ do seu capital de giro financiado por fundos internos, as pequenas representam a maioria (18,78\%), enquanto para aquelas que possuem de $51 \%$ a $100 \%$ do capital de giro financiado, apenas $2,29 \%$ de pequenas empresas são financiadas por bancos privados ou estatais.

Para o financiamento dos ativos fixos, da mesma forma, as pequenas empresas se financiam, em boa parte, pelos fundos internos. No entanto, a maioria das pequenas empresas não possui ativos fixos financiados quando o capital vem de bancos privados ou estatais.

Em suma, esses resultados sugerem que as pequenas empresas possuem dificuldades de conseguir financiamento através de crédito de bancos privados ou estatais. Por exemplo, no financiamento de ativos fixos, o percentual de empresas grandes é 2,6 vezes maior que o percentual de empresas pequenas (ver a coluna 3 da Tabela 4), o que faz com que se concentrem em financiar suas atividades com seus próprios fundos, enquanto as grandes empresas podem não encontrar dificuldades de obter crédito. Na Tabela 8 (ver o Anexo A), são apresentadas outras estatísticas descritivas.

\subsection{Modelo Empírico}

Para se alcançar os resultados, estima-se o modelo probit, que é um modelo de probabilidade não linear, o qual permite estimar os parâmetros das variáveis que explicam uma determinada probabilidade. Sendo $Y$ a variável dependente, utiliza-se, por exemplo, $Y=1$ para empresas exportadoras e $Y=0$ para empresas não exportadoras.

Assume-se, conforme Roberts e Tybout (1997), que cada firma i observa suas características e forma expectativas em relação ao mercado. A firma decidirá exportar ou não dependendo do índice de utilidade não observável. Ii é determinado por uma ou mais variáveis explanatórias $(\mathrm{Xi})$ : acesso ao crédito; idade; tamanho; participação estrangeira; aglomeração; utilização de insumos importados; qualificação da mão de obra; e utilização de e-mail e website. Quanto maior for o índice Ii, maior será a probabilidade de que a empresa decida exportar. 
Para a estimativa do impacto da restrição de crédito, foram utilizadas quatro variáveis proxies para representar as restrições financeiras no modelo. A primeira foi o percentual de capital de giro da empresa financiado por fundos internos. A segunda variável foi o percentual de capital de giro da empresa financiado através de bancos privados ou de propriedade do estado. A terceira variável utilizada foi a proporção da compra de ativos fixos financiada por fundos internos. A quarta variável foi a proporção da compra de ativos fixos financiada por bancos privados ou de propriedade estatal.

O modelo empírico proposto neste trabalho, inspirado em Roberts e Tybout (1997), pode ser escrito como:

$$
\text { Exportador }_{\mathrm{ijk}}\left\{\begin{array}{l}
=1, \text { se exportador } \\
=0, \text { se não exportador }
\end{array}\right.
$$

O status de exportador ocorrerá quando o valor esperado de um conjunto de informações ${ }^{6}$ for maior se a empresa for exportadora do que o valor esperado de um conjunto de informações se a empresa não for exportadora. Sendo que a aplicação do modelo é explicada pelas seguintes variáveis:

$$
\begin{gathered}
\text { Exportador }_{i j k}=\alpha+\beta_{1} \text { finance }_{i j k}+\beta_{2} \text { idade }_{i j k}+\beta_{3} \text { tamanho }_{i j k}+\beta_{4} \text { partestran geira }_{i j k}+ \\
\beta_{5} \text { aglomeraçã }_{i j k}+\beta_{6} \text { insumosimp }_{i j k}+\beta_{7} \text { treinament }_{i j k}+\beta_{8} \text { webmail }_{i j k}+\mu_{k}+e_{i}
\end{gathered}
$$

em que Exportador ${ }_{i j k}$ significa que a empresa i do setor $j$ localizada no país $k$ possui status de exportadora; finance, nesta pesquisa, representa o acesso ao crédito por parte das firmas e é capturado pela proporção do capital de giro e financiamento de ativos fixos tanto por fundos externos quanto por fundos internos, conforme Kuntchev et al. (2012), Kinda (2013) e Manole e Spatareanu (2015). Sobre essa proxy para acesso financeiro, Ramalho, Meza e Yang (2014) destacam que, em geral, as firmas precisam de recursos e serviços financeiros para investimento e/ou gestão do fluxo de caixa, no entanto muitas vezes as firmas não possuem recursos suficientes no momento em que a necessidade surge. Assim, as firmas buscam financiamento externo junto às instituições financeiras e outras formas, logo bom acesso financeiro pode ser crucial para as operações empresariais, principalmente devido ao descasamento dos prazos entre receitas de vendas (exportações) e as despesas para produção.

Ainda sobre a equação 5, a variável idade corresponde à quantidade de anos desde a fundação da empresa até a data de realização da pesquisa, então representa o background e a reputação da firma; tamanho corresponde a uma dummy de valor um para as empresas que possuem tamanho médio ou grande (acima de 20 trabalhadores) e zero para as de tamanho pequeno; partestrangeira é a variável que indica que a empresa possui participação estrangeira acima de 10\% no seu capital

6 Para uma apresentação detalhada, ver o modelo teórico na seção 2.1. 
de giro (conforme o padrão do FMI); aglomeração é a concentração de empresas exportadoras por setor em cada local, capta o efeito spillover setorial; insumosimp é o logaritmo natural da variável que indica o percentual de insumos e suprimentos de origem estrangeira; treinamento é o logaritmo natural do percentual de qualificação da mão de obra empregada de maneira permanente e em tempo integral na produção; webmail é uma dummy que possui valor um para as empresas que se utilizam de e-mail e website para comunicação com fornecedores e clientes e zero para as que não utilizam nenhum dos dois ou utilizam somente um dos meios de comunicação; representa os efeitos fixos controlados para países; e é o termo de erro.

\section{Estimativas e Resultados}

Na presente seção, apresentam-se os resultados das estimativas do modelo probit. Pretende-se verificar os efeitos da restrição ao crédito sobre a probabilidade de determinada firma i possuir o status de exportadora, dadas as características das empresas que influenciam a probabilidade de a empresa entrar no mercado exportador, como, por exemplo, o tamanho que reflete a escala de produção.

A Tabela 5 apresenta os resultados das regressões que utilizam as variáveis capital de giro e ativos permanentes tendo como fonte de financiamento os bancos privados ou estatais.

Tabela 5 - Probit: financiamento por bancos privados ou estatais e a probabilidade de exportação

\begin{tabular}{lcc}
\hline Variáveis & $(1)$ & $(2)$ \\
\hline Financiamento do capital de giro & $0,0382^{* * *}$ & \\
Financiamento dos ativos fixos & $(0,00122)$ & \\
& & $0,0267^{* * *}$ \\
Idade & & $(0,000964)$ \\
& $0,00187^{* *}$ & 0,000774 \\
Tamanho & $(0,000849)$ & $(0,00115)$ \\
& 0,0663 & 0,0614 \\
Partestrangeira & $(0,0983)$ & $(0,128)$ \\
& $0,429^{* * *}$ & $0,477^{* * *}$ \\
Aglomeração & $(0,0755)$ & $(0,0963)$ \\
Insumosimp & 0,000163 & $-0,000176$ \\
Treinamento & $(0,000508)$ & $(0,000634)$ \\
& $-0,0196$ & 0,00453 \\
Webmail & $(0,0162)$ & $(0,0192)$ \\
& 0,00203 & $-0,00376$ \\
& $(0,0229)$ & $(0,0267)$ \\
& 0,102 & $0,181^{*}$ \\
& $(0,0664)$ & $(0,0974)$ \\
\hline
\end{tabular}


Conclusão.

\begin{tabular}{lcc}
\hline Efeitos fixos & Sim & Sim \\
\hline Validade dos instrumentos & & \\
\hline Estatística de Cragg-Donald & 16,383 & 9,067 \\
\hline Observações & 4.722 & 3.161 \\
\hline
\end{tabular}

Fonte: Elaboração própria a partir de The World Bank (2016).

Notas: Erros padrões robustos entre parênteses; ${ }^{* * *} \mathrm{p}<0,01,{ }^{* *} \mathrm{p}<0,05,{ }^{*} \mathrm{p}<0,1$; efeitos fixos para países são controlados.

A partir das estimativas apresentadas na Tabela 5, pode-se constatar que tanto o mercado de crédito de curto prazo (capital de giro) quanto o de longo prazo (ativos fixos) podem afetar as chances das empresas se tornarem exportadoras. Contudo, observa-se que a variável que indica o percentual de capital de giro financiado pelos bancos privados ou estatais tem impacto maior na probabilidade de as empresas serem exportadoras. Ambas as variáveis são estatisticamente significativas a $1 \%$ e indicam que um aumento de um ponto percentual no financiamento do capital de giro por bancos ocasionará um aumento de aproximadamente $4 \%$ na probabilidade de exportar. $\mathrm{O}$ aumento de um ponto percentual no financiamento de ativos fixos por bancos levará a um aumento de pouco mais de $2,5 \%$ na probabilidade dessas empresas exportarem. Deve-se ressaltar que esse resultado independe do porte da firma, sendo que a variável de controle tamanho não se apresentou como estatisticamente significativa. Ramalho, Meza e Yang (2014) ressaltam que as firmas precisam de recursos financeiros para investimentos ou gestão do fluxo de caixa, e como nem sempre têm fundos suficientes, recorrem a fontes de recursos externos. Esses resultados são consistentes com a literatura, como por exemplo, com o estudo de Minetti e Zhu (2011).

É provável que as firmas que são grandes exportadoras têm maior acesso financeiro. Nesse caso, pode surgir o problema de endogeneidade oriunda da causalidade reversa entre exportações e acesso financeiro. Para contornar o problema de endogeneidade, utiliza-se como instrumento para a variável finance a dummy externaudit, que indica se a empresa $i$ qualquer passou por processo de auditoria externa das suas demonstrações financeiras no ano anterior ao da pesquisa. $O$ fato de a firma ser auditada traz maior confiança sobre as demonstrações dos resultados financeiros por parte das instituições financeiras, dessa forma a dummy que representa auditoria externa se apresenta como um instrumento porque pode influenciar na obtenção de recursos externos. Um procedimento similar foi utilizado por Kinda (2013).

A variável partestrangeira apresentou relação positiva com as chances de a empresa ser uma exportadora, o que significa que a presença de capital estrangeiro aumenta em aproximadamente $4,3 \%$ a probabilidade de a empresa ser exportadora (estimativa 1), enquanto que, quando considera-se o financiamento dos ativos fixos por bancos, a probabilidade é aumentada em aproximadamente 4,8\% 
(estimativa 2). Ou seja, se a empresa é multinacional ou uma joint venture, tem mais chances de ser uma exportadora.

A variável tamanho não foi significativa nos dois modelos, demonstrando que as economias de escala não são relevantes para os países em análise. A variável que indica a utilização de e-mail e websites para comunicação, networking externo, é significativa em uma das especificações. As demais variáveis de controle, como aglomeração, insumosimp e treinamento não foram estatisticamente significantes. Nas duas estimativas apresentadas, o teste estatístico F de Cragg-Donald indica que é possível rejeitar a hipótese nula de que os instrumentos são fracos.

$\mathrm{Na}$ Tabela 6 são apresentados os resultados das estimativas relacionando probabilidade de exportação com financiamento realizado a partir de fundos internos.

Tabela 6 - Probit: financiamento por fundos internos e probabilidade de exportação

\begin{tabular}{|c|c|c|c|c|}
\hline \multicolumn{5}{|l|}{ Variáveis } \\
\hline & $(1)$ & (2) & (3) & (4) \\
\hline \multirow[t]{2}{*}{ Financiamento do capital de giro (1) } & $-0,0276 * * *$ & & & \\
\hline & $(0,000196)$ & & & \\
\hline \multirow[t]{2}{*}{ Financiamento do capital de giro (2) } & & $0,0235 * * *$ & & \\
\hline & & $(0,000970)$ & & \\
\hline \multirow[t]{2}{*}{ Financiamento dos ativos fixos (1) } & & & $-0,0241 * * *$ & \\
\hline & & & $(0,000351)$ & \\
\hline \multirow[t]{2}{*}{ Financiamento dos ativos fixos (2) } & & & & $0,0224 * * *$ \\
\hline & & & & $(0,000582)$ \\
\hline \multirow[t]{2}{*}{ Idade } & $0,00167 * *$ & & 0,00129 & \\
\hline & $(0,000811)$ & & $(0,00112)$ & \\
\hline \multirow[t]{2}{*}{ Tamanho } & $-0,116$ & $0,453 * * *$ & 0,0285 & $0,353^{* * *}$ \\
\hline & $(0.0965)$ & $(0.0714)$ & $(0,127)$ & $(0,0828)$ \\
\hline \multirow[t]{2}{*}{ Partestrangeira } & $0,220 * * *$ & $0,105^{*}$ & $0,348 * * *$ & $-0,00362$ \\
\hline & $(0,0826)$ & $(0,0550)$ & $(0,102)$ & $(0,0632)$ \\
\hline \multirow[t]{2}{*}{ Aglomeração } & 0,000335 & $0,00164 * * *$ & $-3,84 \mathrm{e}-05$ & $0,00155 * * *$ \\
\hline & $(0,000463)$ & $(0,000445)$ & $(0,000581)$ & $(0,000506)$ \\
\hline \multirow[t]{2}{*}{ Insumosimp } & $-0,0102$ & & $-0,0179$ & \\
\hline & $(0,0149)$ & & $(0,0180)$ & \\
\hline \multirow[t]{2}{*}{ Treinamento } & 0,0326 & $-0,0883^{* * *}$ & 0,0253 & $-0,0597^{* * *}$ \\
\hline & $(0,0212)$ & $(0,0187)$ & $(0,0257)$ & $(0,0225)$ \\
\hline \multirow[t]{2}{*}{ Webmail } & $-0,0152$ & $0,313^{* * *}$ & 0,0492 & $0,219 * * *$ \\
\hline & $(0,0669)$ & $(0,0582)$ & $(0,100)$ & $(0,0715)$ \\
\hline Efeitos fixos & Sim & Não & $\operatorname{Sim}$ & Não \\
\hline \multicolumn{5}{|l|}{ Validade dos instrumentos } \\
\hline Estatística de Cragg-Donald & 0,507 & 15,838 & 2,119 & 7,134 \\
\hline Observações & 4.722 & 6.744 & 3.161 & 4.187 \\
\hline
\end{tabular}

Fonte: Elaboração própria a partir de The World Bank (2016).

Notas: Erros padrões robustos entre parênteses; ** $\mathrm{p}<0,01$, ** $\mathrm{p}<0,05,{ }^{*} \mathrm{p}<0,1$; efeitos fixos para países são controlados. 
Nas estimativas da Tabela 6, a variável finance é representada por recursos de fundos internos. Nas especificações que controlam os efeitos fixos dos países (efeitos não observáveis), o coeficiente é estatisticamente significante e apresenta sinal negativo (estimativas 1 e 3). Esse resultado indica que, quando maior a dependência de financiamentos originados de fundos próprios, menores são as chances de as empresas serem exportadoras. Já nas estimativas 2 e 4, nas quais não são controlados os efeitos fixos dos diferentes países, os coeficientes são estatisticamente significantes e positivos, indicando que as chances de as empresas serem exportadoras se dão quando o volume de capital de giro e de ativos fixos financiados pelos fundos próprios for maior.

As diferentes especificações são também devido ao teste $F$ de Cragg-Donald, que apresentou baixo valor crítico, sugerindo ajuste na especificação da estimativa 1. A estimação de variáveis instrumentais com instrumentos fracos implica que os desvios padrões serão muito grandes.

Nas especificações 2 e 4, substituiu-se a variável auditoria externa (externaudit) usada como instrumento para a variável financeira, que passou a ser a idade das empresas. Essa variável capta a reputação da firma no mercado. Para essas estimativas (2 e 4), o teste indicou os instrumentos como válidos.

Nessa especificação, o tamanho, que foi a variável proxy para economias de escala, indica que as firmas grandes têm maior probabilidade de serem exportadoras. A variável webmail apresentou coeficientes positivos, então implica que as empresas são mais propensas a exportar se elas se beneficiam de redes de comunicação, o que está em consonância com a literatura, como, por exemplo, com o estudo de Ricci e Trionfetti (2012).

Quanto à aglomeração de empresas exportadoras por setor em cada local, foi estatisticamente significante nas regressões 2 e 4 , indicando que existem externalidades positivas para a empresa se esta se localizar na vizinhança de outras exportadoras (spillovers), e que o background da empresa também influencia o status exportador.

Os resultados apresentados estão em linha com a literatura empírica (BELLONE et al., 2008; CAVA, 2010; MINETTI; ZHU, 2011; MANOVA; WEI; ZHANG, 2011) e são estáveis em diferentes especificações empíricas. Em suma, constatou-se que o acesso ao crédito pode afetar positivamente a probabilidade de uma empresa ser exportadora, no entanto, quando a variável finance é representada pelos fundos internos usados para capital de giro e/ou investimento, o resultado é sensível à presença da variável usada como instrumento.

Quanto à distribuição das firmas, vale destacar o fato de que as pequenas empresas apresentam menor capacidade de financiamento do seu capital de giro através de crédito emprestado de bancos privados ou estatais (ver Tabela 4). Para os ativos fixos, percebe-se que as empresas de porte médio e grande têm maior autonomia e capacidade de se financiar através de recursos próprios. Da média 
para a grande empresa, não há tanta diferença, porém as pequenas empresas localizam-se mais nas proporções menores de ativos fixos financiados, independente da fonte de financiamento.

Conhecidos os impactos pela magnitude dos coeficientes, adicionalmente analisa-se as variáveis foco a partir da apresentação do comportamento dos efeitos marginais de variações na variável finance (uso de recursos financeiros de fontes externas ou internas). Na Figura 1, verifica-se o efeito marginal do capital de giro (a) e dos ativos fixos (b) financiados por bancos privados ou estatais nas probabilidades de a empresa ser exportadora. Quando se trata de capital de giro, o impacto na probabilidade de exportação é mais rápido, porém o retorno se torna estável mais rapidamente que quando se trata de ativos fixos. Nesse caso, a empresa passa de não exportadora para exportadora de forma mais lenta.

Figura 1 - Efeitos marginais para capital de giro (a) e ativos fixos (b) financiados por bancos privados ou estatais
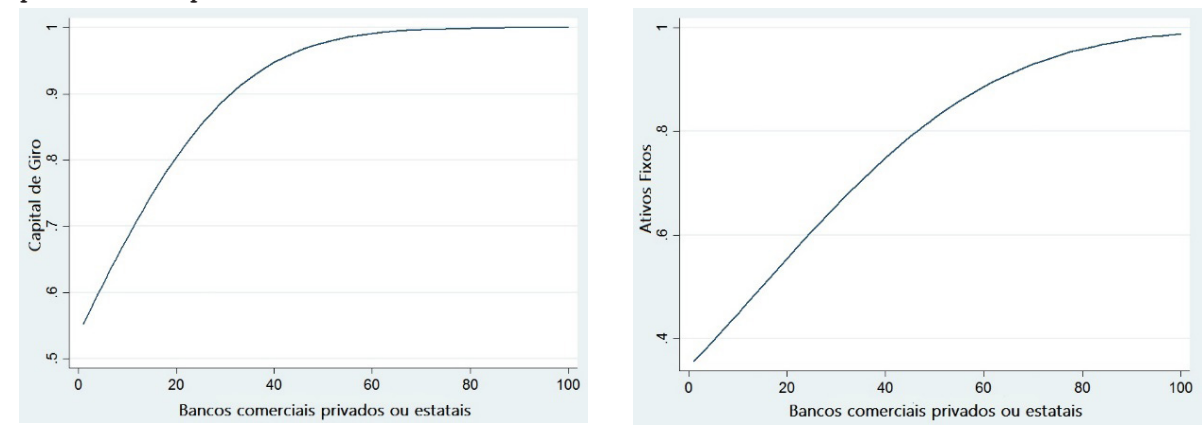

Fonte: Elaboração própria a partir de The World Bank (2016).

A Figura 2 trata do efeito marginal quando o financiamento se dá por fundos internos da empresa. Para ativos fixos ou capital de giro, a diferença no efeito marginal não é grande, então a probabilidade de a empresa se tornar exportadora aumenta com menor velocidade, porém não ocorre estabilização do efeito marginal. 
Figura 2 - Efeitos marginais para capital de giro (a) e ativos fixos (b) financiados por fundos próprios
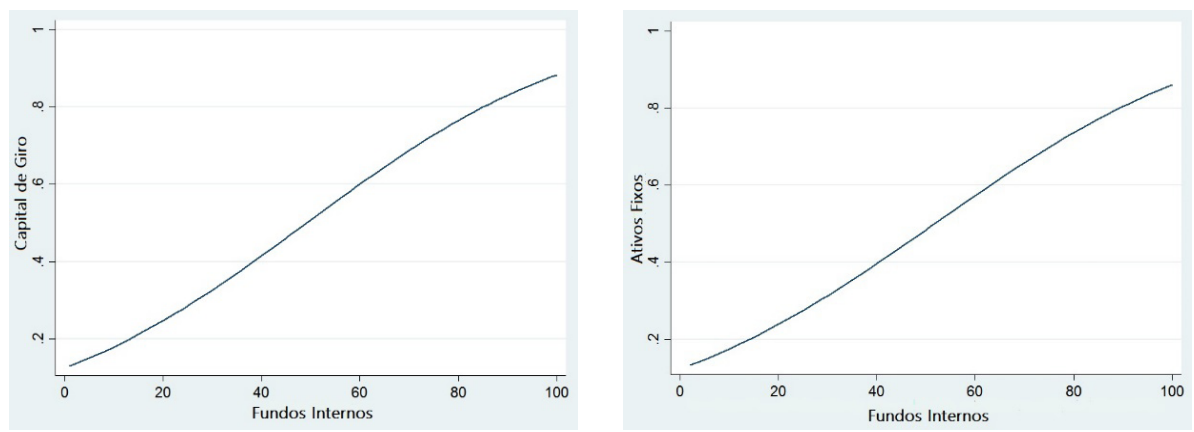

Fonte: Elaboração própria a partir de The World Bank (2016).

Esse resultado demonstra que o efeito marginal é maior quando se trata de financiamento externo (bancos privados ou estatais). Isso significa que, quando as empresas conseguem financiamento externo, seja para investimentos, seja para gestão de fluxo de caixa, têm maiores chances de se tornarem exportadoras. Nos dados constantes na Tabela 4, é possível verificar que as empresas pequenas têm maiores restrições de crédito, pois se concentram na faixa de maior financiamento por fundos próprios e menor financiamento por bancos privados ou estatais. Já as empresas médias e grandes que têm menor restrição de crédito para enfrentar os custos de participar do mercado internacional têm também maior acesso ao mercado externo para suas exportações.

Buscando-se verificar a robustez dos resultados estimados pelo modelo probit, foram reestimadas regressões utilizando-se o procedimento tobit. Esse procedimento é utilizado nos casos em que a variável dependente é contínua e observada apenas dentro de um certo intervalo numérico ocasionado por uma forma de censura nas observações, como, por exemplo, nesse caso em que as exportações diretas se classificam entre 0 e 100 por cento do total das vendas da firma. Verifica-se que os coeficientes se mantêm estáveis à mudança no método, visto que os resultados das regressões (ver a Tabela 7 no Anexo A) confirmam o impacto positivo do acesso ao crédito nas exportações.

As variáveis de controle como a participação estrangeira do capital, a idade da firma e o acesso ao crédito apresentaram os mesmos resultados e estão em linha com os estudos de Bellone et al. (2008), Cava (2010), Minetti e Zhu (2011) e Manova, Wei e Zhang (2011). Para novas etapas na agenda de pesquisa, espera-se obter dados atuais das grandes economias da região da América Latina, além de novas variáveis para instrumentos. 


\section{Considerações Finais}

O presente estudo buscou verificar a relação das restrições de crédito, representadas pelo uso de fundos para capital de giro e investimento e a probabilidade de exportação das empresas no setor industrial. A estratégia de estimação foi implementada controlando outras variáveis de características da firma que são relevantes, como idade, tamanho, participação estrangeira na estrutura de capital, aglomeração de empresas do mesmo setor em uma mesma região (spillovers), utilização de insumos importados na produção, qualificação da mão de obra utilizada na produção e utilização de e-mails e websites para comunicação com clientes e fornecedores. Também, utilizou-se uma dummy de efeitos fixos para países para se controlar choques comuns aos setores, mas que impactam de forma diferenciada cada país. A análise é feita a partir do modelo de probabilidade (probit) para 18 países da América Latina, com dados em nível micro de 7.764 firmas do setor industrial.

Os resultados indicam, em média, que o acesso ao crédito é positivamente associado à probabilidade de participação das firmas no mercado internacional. Essas estimativas são robustas às diferentes especificações. Quando se mede o acesso ao crédito pela proporção do capital de giro que as empresas têm financiado junto a bancos privados ou estatais, ou seja, uso de recursos externos para gestão de fluxo de caixa, o impacto é positivo sobre a probabilidade de exportação. Esse resultado indica que firmas de menor porte (pequenas e médias) são beneficiadas com a possibilidade de um maior acesso financeiro, pois demonstram certa dependência de fontes externas para gestão do capital de giro (ver a Tabela 4). Quanto às variáveis que representam investimentos (ativos fixos) financiados, apresentaram impacto positivo do acesso ao crédito na probabilidade de exportação. Quanto às demais variáveis de controle que são características das empresas, constata-se que firmas maiores e com participação estrangeira na estrutura do capital têm mais chances de se tornarem exportadoras.

A presente pesquisa contribui para a literatura apresentando novas evidências a partir de dados em nível microeconômico para países da América Latina, por ser informações em nível de firmas individuais constata o impacto do acesso ao crédito na probabilidade da empresa exportar, uma vez controlado características das firmas como tamanho, idade e produtividade.

Dessa forma, com o objetivo de melhorar o desenvolvimento econômico e o bem-estar de cada país via aumento de exportações, é pertinente formular políticas que ampliem o acesso das empresas ao mercado financeiro, principalmente ao desenvolvimento financeiro voltado para as empresas pequenas e médias, que apresentaram maior dependência de recursos externos para gestão de fluxo de caixa e investimento. Os recursos para a gestão de fluxo de caixa são importantes considerando-se os descasamentos de prazos entre contratação de insumos, por 
exemplo, e a receita das vendas. Essa é uma das formas de promover uma maior participação das empresas no mercado internacional. Como sugestão para pesquisas futuras, é possível avançar com disponibilização de informações sobre as firmas para outros anos. Isso permitirá uma análise dinâmica do comportamento exportador e do impacto do acesso ao crédito na permanência da firma no mercado internacional.

\section{Referências}

ALVAREZ, R. B. P. Instrumentos públicos de incentivo às exportações e desempenho de estreantes no mercado internacional. 2013. 120 f. Dissertação (Mestrado em Economia) - Faculdade de Economia, Administração e Contabilidade de Ribeirão Preto, Universidade de São Paulo, Ribeirão Preto, 2013.

ALVAREZ, R.; LÓPEZ, R. A. Access to banking finance and exporting. Industrial and Corporate Change, v. 23, n. 6, p. 1523-1539, 2014.

BANCO MUNDIAL. Enterprise surveys data. 2010. Disponível em: http://www.enterprisesurveys.org/data. Acesso em: 15 abr. 2018

BELLONE, F.; MUSSO, P.; NESTA, L.; SCHIAVO, S. Financial constraints and firm export behavior. Sciences Po Department of Economics Working Papers, n. 16, 2008.

BERMAN, N.; HÉRICOURT, J. Financial factors and the margins of trade: evidence from cross-country firm-level data. Journal of Development Economics, n. 93, p. 206-217, 2010.

BERNARD, A.; JENSEN, B. Why some firms export. The Review of Economics and Statistics, v. 86, n. 2, p. 561-569, 2004.

BRAUN, M. Financial contractability and asset hardness. SSRN, n. 2522890, 2005.

CASTAGNINO, T.; D'AMATO, L.; SANGIÁCOMO, M. How do firms in Argentina get financing to export? European Central Bank Working Paper, n. 1601, 2013.

CAVA, P. B. Determinantes da atividade exportadora: uma análise das empresas paulistas. 2010. Dissertação (Mestrado em Engenharia de Produção) - Escola de Engenharia de São Carlos, Universidade de São Paulo, São Carlos, 2010.

CIANI, A.; BARTOLI, F. Export quality upgrading and credit constraints. In: ANNUAL CONFERENCE OF EUROPEAN TRADE STUDY GROUP (ETSG), 15., 2013. Birmingham. Proceedings [...]. Disponível em: https://www.etsg.org/ETSG2013/ETSG2013Programme.htm. Acesso em: 1 maio 2018.

CLAESSENS, S.; LAEVEN, L. Financial development, property rights, and growth. Journal of Finance, v. 58, n. 6, p. 2401-2436, 2003. 
COLE, M. A.; ELLIOT, R. J. L.; VIRAKUL, S. Exporting and financial health: a developing country perspective. In: ANNUAL ETSG CONFERENCE, 10, 2008, Varsóvia. Anais eletrônicos [...]. Varsóvia: University of Warsaw: Warsaw School of Economics, 2008. p. 11-13.

CRAGG, J. C.; DONALD, S. G. Testing identiafiability and specification instrumental variable models. Econometric Theory, v. 9, n. 2, p. 222-240, 1993.

DE NEGRI, J. A. Desempenho exportador das firmas industriais no brasil: a influência da eficiência de escala e dos rendimentos crescentes de escala. Texto para Discussão IPEA, n. 997, 2003.

DU, J.; GIRMA, S. Finance and firm export China. Kyklos, v. 60, n. 1, p. 37-54, 2007.

FAUCEGLIA, D. Credit constraints, firm exports and financial development: evidence from developing countries. The Quarterly Review of Economics and Finance, v. 55, p. 53-66, 2015.

GREENAWAY, D.; GUARIGLIA, A.; KNELLER, R. Financial factors and exporting decisions. Journal of Internacional Economics, v. 73, n. 2, p. 377-395, 2007.

HASAN, S. M. Credit constraints, technology choice and exports: a firm level study for latin american countries. In: AAEA 8 CAES JOINT ANNUAL MEETING, 2013, Washington. Anais eletrônicos [...]. Washington: AAEA, 2013.

KANNEBLEY JÚNIOR, S.; ESTEVES, L. A.; SILVA, A. M. P.; ARAÚJO, B. C. Auto-seleção e aprendizado no comércio exterior das firmas industriais brasileiras. Economia, v. 10, n. 4, 2009.

KIENDREBEOGO, Y.; MINEA, A. Financial factors and manufacturing exports: theory and firm-level evidence from Egypt. [S. l.]: Hal Sciences de l'Homme et de la Société, 2013. Disponível em: https:/halshs.archives-ouvertes.fr/halshs-00710718v2 Acesso em: 24 jul. 2016.

KINDA, T. Beyond natural resources: horizontal and vertical FDI diversification in Sub-Saharan Africa. Applied Economics, v. 45, n. 25, p. 3587-3598, 2013.

KUNTCHEV, V.; RAMALHO, R.; RODRÍGUEZ-MEZA, J.; YANG, J. S. What have we learned from the enterprise surveys regarding access to finance by SMEs? World Bank Working Papers, n. 68292, 2012. Disponível em: http://documents1.worldbank.org/curated/en/958291468331867463/pdf/6 82920WP0Box360s0toofinance0andoSME.pdf Acesso em: 23 jun. 2016.

LANCHEROS, S.; DEMIREL, P. Does finance play a role in exporting for service firms? Evidence from India. The World Economy, v. 35, n. 1, p. 44-60, 2012.

LI, Z.; YU, M. Exports, productivity, and credit constraints: a firm-level empirical investigation of China. SSRN Eletronic Journal, n. 6, 2009.

LIMA, J. D.; HERREROS, S; MULDER, N. Comércio de serviços de América Latina e no Caribe: como se aproximar do dinamismo mundial? Revista Brasileira de Comercio Exterior, v. 106, p. 19-28, 2011.

MANOLE, V.; SPATAREANU, M. Investment climate, foreign networks and exporting: evidence from Africa. Internacional Review of Applied Economics, v. 29, n.3, p. 349-373, 2015. 
MANOVA, K.; WEI, S.; ZHANG, Z. Firm exports and multinational ac

gate industry productivity. Econometrica, v. 71, n. 6, p. 1695-1725, 2003.

MINETTI, R.; ZHU, S. C. Credit constraints and firm export: microeconomic evidence from Italy. Journal of International Economics, v. 83, n. 2, p. 109-125, 2011.

MUÛLS, M. Exporters and credit constraints. A firm level approach. NBB working papers, n. 139, 2008.

PINHEIRO, A. C.; MOREIRA, M. M. O perfil dos exportadores brasileiros de manufaturados nos anos 90: quais as implicações de política? BNDES Texto para Discussão, n. 80, 2000.

RAMALHO, R.; MEZA, J. R.; YANG, J. Obtaining finance in Latin America and the Caribbean. World Bank: Latin America and the Caribbean Series Note, n. 5, 2014.

RAJAN, R.; ZINGALES, L. Financial dependence and growth. American Economic Review, v. 88, n. 3, p. 559-86, 1998.

RICCI, L. A.; TRIONFETTI, F. Productivity, networks, and export performance: evidence from a cross-country firm dataset. Review of Internacional Economics, v. 20, n. 3, p. 552-562, 2012.

ROBERTS, M. J.; TYBOUT, J. R. The decision to export in Colombia: an empirical model of entry with sunk costs. The American Economic Review, v. 87, n. 4, p. 545-564, 1997.

STIEBALE, J. Do financial constraints matter for foreign market entry? A firm-level examination. The World Economy, v. 34, n. 1, p. 123-153, 2011.

THE WORLD BANK. World development indicators. 2016. Disponível em: http://data.worldbank.org/data-catalog/world-development-indicators. Acesso em: 15 jul. 2016.

THE WORLD BANK. Enterprise surveys data. 2010. Disponível em: http://www.enterprisesurveys.org/data. Acesso em: 20 abr. 2016.

UNCTAD. Data Center. Switzerland, [2016]. Disponível em: http://unctadstat.unctad.org/ wds/ReportFolders/reportFolders.aspx?IF_ActivePath=P,15912E3sCS_ChosenLang $=$ en. Acesso em: 14 out. 2016.

VALERI, J. O. Impactos da atividade inovativa sobre a permanência das firmas industriais brasileiras no mercado externo. 2006. Dissertação (Mestrado em Economia) - Faculdade de Economia, Administração e Contabilidade de Ribeirão Preto, Universidade de São Paulo, Ribeirão Preto, 2006.

WAGNER, J. Exports and productivity: a survey of the evidence from firm-level data. The World Economy, v. 30, n. 1, p .60-82, 2007.

WANG, X. Financial constraints and exports. SSRN working paper, n. 2698358, 2016. Disponível em: SSRN: https://ssrn.com/abstract=2698358. Acesso em: 20 abr. 2017. 


\section{Anexo A}

Tabela 7 - Regressões do modelo tobit

\begin{tabular}{|c|c|c|c|c|}
\hline Variáveis & & & & \\
\hline $\begin{array}{l}\text { Financiamento do capital de giro por } \\
\text { bancos privados ou pelo Estado }\end{array}$ & $3,102^{* * *}$ & & & \\
\hline & $(0,893)$ & & & \\
\hline $\begin{array}{l}\text { Financiamento do capital de giro por } \\
\text { fundos internos }\end{array}$ & & $2,245 * * *$ & & \\
\hline & & $(0,847)$ & & \\
\hline $\begin{array}{l}\text { Financiamento dos ativos fixos por } \\
\text { bancos privados ou pelo Estado }\end{array}$ & & & $1,118^{* *}$ & \\
\hline & & & $(0,472)$ & \\
\hline $\begin{array}{l}\text { Financiamento dos ativos fixos por } \\
\text { fundos internos }\end{array}$ & & & & \\
\hline & & & & $(0,723)$ \\
\hline Idade & 0,0352 & $-0,0757$ & & \\
\hline & $(0,0602)$ & $(0,0859)$ & & \\
\hline Tamanho & 11,99 & 8,099 & $44,23 * * *$ & $44,05^{* * *}$ \\
\hline & $(7,464)$ & $(9,774)$ & $(3,946)$ & $(5,909)$ \\
\hline Partestrangeira & $40,21 * * *$ & $43,80 * * *$ & $18,20 * * *$ & $12,36^{* *}$ \\
\hline & $(4,995)$ & $(7,735)$ & $(2,761)$ & $(5,329)$ \\
\hline Aglomeração & $-0,0344$ & $-0,0654$ & $0,141^{* * *}$ & $0,165^{* * *}$ \\
\hline & $(0,0416)$ & $(0,0543)$ & $(0,0270)$ & $(0,0425)$ \\
\hline Insumosimp & $-3,627^{* * *}$ & $-1,743$ & & \\
\hline & $(1,387)$ & $(1,651)$ & & \\
\hline Treinamento & $-0,00781$ & $-0,191$ & $-6,736 * * *$ & $-6,049 * * *$ \\
\hline & $(1,840)$ & $(2,229)$ & $(1,692)$ & $(2,229)$ \\
\hline Webmail & $10,51 * *$ & $17,56 * * *$ & $28,23 * * *$ & $27,68^{* * *}$ \\
\hline & $(4,321)$ & $(5,057)$ & $(2,920)$ & $(3,799)$ \\
\hline Efeitos fixos & Sim & Sim & Não & Não \\
\hline Observações & 4.719 & 3.159 & 6.740 & 4.185 \\
\hline
\end{tabular}

Fonte: Elaboração própria a partir de The World Bank (2016).

Notas: Erros padrões robustos entre parênteses; ${ }^{* * *} p<0,01,{ }^{* *} p<0,05,{ }^{*} p<0,1$; efeitos fixos para países são controlados.

Tabela 8 - Estatística descritiva das variáveis do modelo

\begin{tabular}{lccccc}
\hline Variável & Observações & Média & Desvio padrão & Mínimo & Máximo \\
\hline Idade & 7729 & 27,14 & 21,02 & 0,00 & 340,00 \\
Participação & 7304 & 9,46 & 27,82 & 0,00 & 100,00 \\
estrangeira & 7764 & 47,43 & 36,28 & 0,00 & 135,00 \\
Aglomeração & & & & Continua \\
\hline
\end{tabular}

Continua... 


\begin{tabular}{lccccc}
\hline Variável & Observações & Média & Desvio padrão & Mínimo & Máximo \\
\hline Insumos importados & 7411 & 31,80 & 33,14 & 0,00 & 100,00 \\
Treinamento & 6840 & 3,98 & 0,73 & $-0,10$ & 4,61 \\
Webmail & 7747 & 0,66 & 0,47 & 0,00 & 1,00 \\
Capital de giro & 7690 & 17,60 & 26,73 & 0,00 & 100,00 \\
Ativos fixos & 4725 & 26,77 & 38,18 & 0,00 & 100,00 \\
\hline
\end{tabular}

Fonte: Elaboração própria a partir de The World Bank (2016).

\section{Autor correspondente:}

Gilberto Joaquim Fraga

Recebido em: 12/10/2018.

E-mail: gjfraga@uem.br

Aceito em: 08/07/2019.

(cc) BY 